\title{
Studies on cytopathic effects of BmNPV infection in three lepidopteran insect cell lines in MGM-448 medium
}

\author{
Syed Obaid Qureshi* \\ Department of Zoology, Adarsha Science, J. B. Arts and Birla Commerce College, Dhamangaon Rly. District Amravati, India
}

\section{ARTICLE INFO \\ Article history: \\ Received on: April 05, 2020 \\ Accepted on: May 13, 2020 \\ Available online: May 26, 2020}

\section{Key words:}

Cytopathic effects, serial passaging, susceptibility, insect cell line, DZNU-Bm-1.

\begin{abstract}
Three insect cell lines, namely, DZNU-Bm-1, DZNU-Bm-12, and NIAS-MaBr-92, were tested for susceptibility to Bombyx mori nucleopolyhedrovirus (BmNPV). The cytopathic effects of infection on cultured cells were observed. BmNPV was then serially passaged in these cell lines to assess their long-term ability to support BmNPV replication. The cell lines were cultured in MGM- 448 medium supplemented with $10 \%$ fetal bovine serum. Virus inoculum was prepared from B. mori larvae infected with BmNPV. The early signs of infection started appearing within 16-36 hours post inoculation (hr pi). DZNU-Bm-1 and DZNU-Bm-12 cells showed heavy clumping. NIAS-MaBr-92 cells lost their motility and tended to form loose aggregations. Cytopathic effects such as hypertrophy of nuclei and increase in cell size were prominent in all three cell lines. Beginning of occlusion body (OB) formation in DZNU-Bm-1 was first observed at about 36-42 hr pi, whereas, in DZNU-Bm-12, they were observed only after $42 \mathrm{hr}$ pi. NIAS-MaBr-92 cells exhibited OB formation only after $84 \mathrm{hr}$ pi. The large mature OBs were visible in DZNU-Bm-1 cells by $66 \mathrm{hr}$ pi, whereas, in DZNU-Bm-12 cells by $72 \mathrm{hr}$ pi. Mature OBs were observed in NIAS-MaBr-92 cells only after $120 \mathrm{hr}$ pi. A number of OBs per cell varied from 12 to 82 in DZNU-Bm-1, 3 to 23 in DZNU-Bm-12, and 3 to 14 in NIAS-MaBr-92 cells. In this study, DZNU-Bm-1 and DZNU-Bm-12 cell lines were found to be better than NIAS-MaBr-92 in terms of percentage infection. The yield of OBs per infected cell is also the highest in DZNU-Bm-1, whereas DZNU-Bm-12 and NIAS-MaBr-92 have comparable yields of OBs per cell.
\end{abstract}

\section{INTRODUCTION}

Insect cell lines have served a wide range of purposes in areas, such as genetics, cell biology, agriculture, endocrinology, and virology. In recent years, lepidopteran cell lines have been used for the biomanufacturing of proteins of human interest, biopesticides, and vaccines [1-4]. Baculoviruses are DNA viruses that infect arthropods. Many of these baculoviruses have been shown to possess the potential to be used as biopesticides. Two properties of nucleopolyhedroviruses have made them attractive for use as bioinsecticides. First, they are safe for mass spraying because they do not infect vertebrates and other non-target animals [5]. The second desirable property of these baculoviruses is their high pathogenicity [6]. Advances in recombinant DNA technology have now armed researchers with the ability to engineer novel

\footnotetext{
*Corresponding Author

Syed Obaid Qureshi, Department of Zoology, Adarsha Science, J. B. Arts and Birla Commerce College, Dhamangaon Rly. District Amravati, India. E-mail:drsoqureshi@gmail.com
}

nucleopolyhedroviruses with high insecticidal potential [7-9] Baculoviruses are also being employed as gene vectors forming baculovirus expression vector systems (BEVS) [10]. Insect cell lines that have a high susceptibility to a baculovirus can be used to develop efficient insect cell-baculovirus expression vector system (IC-BEVS) [11]. An efficient IC-BEVS production platform can be used for foreign gene expression, production of therapeutic compounds, and vaccines. Bombyx mori nucleopolyhedrovirus (BmNPV) has been successfully utilized in BEVS for the expression of recombinant proteins in susceptible cell lines $[12,13]$. BmNPV has another important economic implication as it causes a devastating disease of silkworms called grasserie. Studying the cytopathic effects and progression of virus replication in permissive cell lines is the first step toward understanding the replication cycle of BmNPV. The studies carried out on the abilities of different baculoviruses to infect heterologous cell lines have given varying results. Helicoverpa armigera nuclear polyhedrosis virus (HaNPV) and BmNPV have been reported to replicate only in respective cell lines and appeared to be highly species specific, 
whereas AcNPV could infect seven cell lines from different insects [14]. However, BmNPV has been shown to replicate in cell line from Mamestra brassicae [15]. In the present study, three insect cell lines [16-18], namely, DZNU-Bm-1, DZNU-Bm-12, and NIAS-MaBr-92, were tested for susceptibility to BmNPV. DZNUBm-1 and DZNU-Bm-12 have been previously used for growth rates and karyotype studies [19]. Cytopathic effects on cultured cells were observed after successful infection with the virus. The BmNPV was then serially passaged in these cell lines to assess their long-term ability to support BmNPV replication.

\section{MATERIALS AND METHODS}

\subsection{Cell Lines}

Three cell lines such as DZNU-Bm-1, DZNU-Bm-12, and NIAS$\mathrm{MaBr}-92$ were cultured in MGM-448 medium supplemented with $10 \%$ fetal bovine serum (FBS). No antibiotics were added to the medium. The cell lines were grown in glass tissue culture flasks, incubated at $25 \pm 1^{\circ} \mathrm{C}$, and passaged regularly.

\subsection{Preparation of Virus Inoculum}

The virus inoculum was prepared from the diseased larvae of silkworm B. mori. Fresh mulberry leaves were cut into pieces of $2 \mathrm{~cm}^{2}$ size. Each piece was then smeared with a $10-\mu 1$ suspension of occlusion bodies (OBs) of BmNPV obtained from the Centre for Sericulture and Biological Pest Management, Ambavihar, R.T.M. Nagpur University, Nagpur. Each smeared piece of leaf was fed to a healthy larva of $B$. mori for inoculation. The larvae were further reared till the fifth instar stage by feeding them with fresh mulberry leaves. At the fifth instar stage, an incision was made on proleg of the inoculated larva to collect hemolymph. After centrifugation (1,000 g for 10 minutes), the supernatant was diluted with an equal volume of MGM-448 medium supplemented with $10 \%$ FBS medium and sterilized by passing through $0.45-\mu \mathrm{m}$ pore size membrane filter. This served as BmNPV inoculum for infecting the cell lines.

\subsection{Inoculation}

BmNPV inoculum was taken in a sterile pipette, and 3-4 drops of it were added to each culture flask containing growing cells. The infected cultures were incubated at $25 \pm 11^{\circ} \mathrm{C}$ and examined for the cytopathic effects and formation of OBs. The contents of the inoculated cultures were collected after 10-12 days post inoculation and centrifuged at 3,000 rpm for 15 minutes. The supernatant containing BmNPV-budded virus was collected in a sterile centrifuge tube. The supernatant was stored in the refrigerator at $4^{\circ} \mathrm{C}$ to be used as a virus inoculum for subsequent passaging of the virus. Serial passaging of virus was carried out by inoculating healthy cells with undiluted supernatant from the previous passage of the virus. Harvesting of OBs was done by resuspending the precipitate containing the infected cells in sterile distilled water, washed with $0.5 \%(\mathrm{w} / \mathrm{v})$ of sodium lauryl sulfate, and rinsed thrice in distilled water.

\subsection{Phase-Contrast Microscopy}

The cultures were examined regularly for the presence of infected cells with a Magnus INVI-inverted phase-contrast microscope. The criterion of BmNPV infection was the presence of polyhedral inclusion bodies in a cell. In cultures that showed heavy clumping of cells, a small number of cells were removed from the inoculated cultures and transferred to microscopic glass slides. The cells were then spread out by placing a cover glass over the slide. From each flask, about 200-300 cells were used for making differential counts of healthy and infected cells. The percentage infection and number of OBs per cell were determined for each cell line.

\section{RESULTS AND DISCUSSION}

The observation of inoculated cultures under phase-contrast microscope indicated that the early signs of infection started appearing within 16-36 hours post inoculation (hr pi). By $24 \mathrm{hr}$ pi, all infected cultures of DZNU-Bm-1 and DZNU-Bm-12 cells showed heavy clumping. Cells from NIAS-MaBr-92 did not show heavy clumping but tended to form loose aggregations. The infected cells of NIAS-MaBr-92 lost their motility. All three cell lines exhibited loose adherence to the bottom of the culture flask. The cytopathic effects such as hypertrophy of nuclei and increase in cell size were prominent in all three cell lines.

The beginning of OB formation in DZNU-Bm-1 was first evidenced from the appearance of refractive bodies in the nuclei of infected cells at about 36-42 hr pi, whereas, in DZNU-Bm-12, they were observed only after $42 \mathrm{hr}$ pi. The nuclei of NIAS-MaBr-92 cells exhibited OB formation only after $84 \mathrm{hr}$ pi. The large mature OBs were visible in the nuclei of aggregated cells of DZNU-Bm-1 by 66 hr pi, whereas in DZNU-Bm-12 cells by $72 \mathrm{hr}$ pi. Mature OBs were observed in NIAS-MaBr-92 cells only after $120 \mathrm{hr}$ pi. OB formation by $40-48 \mathrm{hr}$ pi in $B$. mori cells has been reported in the previous studies [20]. Small OBs have been observed in MB-19 cell line by 52 $\mathrm{hr}$ pi, whereas mature OBs have been reported by $76 \mathrm{hr}$ pi [15]. Some of the cell aggregates were taken out from the infected cultures and examined under a microscope for the determination of the percentage of infected cells. The percentage infection in DZNU-Bm-1 cells remained between $89 \%$ and $93 \%$ (Table 1) for five serial passages of BmNPV. DZNU-Bm-12 cell line showed a consistent percentage infection that ranged from $82 \%$ to $88 \%$ (Table 2). These results agree with other studies that have reported no decrease in the yield of OBs even after 10 passages $[21,22]$. During passage I of virus, about $62 \%$ of NIAS-MaBr-92 cells were infected. The percentage infection gradually increased to $88 \%$ by passage III. It declined thereafter to a level of about $77 \%$ by passage V (Table 3 ). This agrees with the other reports of a decrease in percentage infection and yield of OBs following serial passaging of NPV in permissive cell lines [23-25]. A number of OBs per cell varied from 12 to 82 in DZNU-Bm-1, whereas, in DZNU-Bm-12, it ranged from 3 to 29. The number of OBs per cell depended on the cell size. NIAS-MaBr-92 exhibited about 3 to 19 OBs per infected cell. Infected cells started to lyse by $72 \mathrm{hr}$ pi in DZNU-Bm-1 cells. This is consistent with the previous observations on DZNU-Bm-1 cells [26]. DZNU-Bm-12 cells did not 
Table 1. Five serial passages of BmNPV in DZNU-Bm-1 cells.

\begin{tabular}{|c|c|c|c|c|c|}
\hline Virus passage & Days p.i. & Cells per $\mathrm{ml}\left(\times 10^{5}\right)$ & Percentage infection & Infected cells per $\mathrm{ml}\left(\times 10^{5}\right)^{b}$ & OBs per infected cell \\
\hline I & 4 & 5.22 & 89.86 & 4.69 & $20 \pm 2$ \\
\hline II & 4 & 4.89 & 92.45 & 4.52 & $24 \pm 2$ \\
\hline III & 4 & 4.92 & 90.21 & 4.44 & $20 \pm 3$ \\
\hline IV & 4 & 5.52 & 92.52 & 5.11 & $20 \pm 3$ \\
\hline $\mathrm{V}$ & 4 & 5.68 & 93.21 & 5.29 & $21 \pm 3$ \\
\hline
\end{tabular}

Table 2. Five serial passages of BmNPV in DZNU-Bm-12 cells.

\begin{tabular}{|c|c|c|c|c|c|}
\hline Virus passage & Days p.i. & Cells per $\mathrm{ml}\left(\times 10^{5}\right)$ & Percentage infection ${ }^{\mathrm{a}}$ & Infected cells per $\mathrm{ml}\left(\times 10^{5}\right)^{b}$ & OBs per infected cellc \\
\hline I & 5 & 4.45 & 82.64 & 3.68 & $10 \pm 2$ \\
\hline II & 6 & 4.96 & 86.35 & 4.28 & $09 \pm 2$ \\
\hline III & 6 & 5.06 & 87.16 & 4.41 & $12 \pm 3$ \\
\hline IV & 6 & 5.15 & 88.98 & 4.58 & $12 \pm 2$ \\
\hline $\mathrm{V}$ & 6 & 5.10 & 85.57 & 4.31 & $11 \pm 2$ \\
\hline
\end{tabular}

Table 3. Five serial passages of BmNPV in NIAS-MaBr-92 cells.

\begin{tabular}{|c|c|c|c|c|c|}
\hline Virus passage & Days p.i. & Cells per $\mathrm{ml}\left(\times 10^{5}\right)$ & Percentage infection ${ }^{a}$ & Infected cells per $\mathrm{ml}\left(\times 10^{5}\right)^{b}$ & OBs per infected cell \\
\hline I & 9 & 5.51 & 62.23 & 3.43 & $08 \pm 2$ \\
\hline II & 7 & 5.20 & 78.87 & 4.10 & $09 \pm 2$ \\
\hline III & 7 & 5.24 & 88.44 & 4.63 & $13 \pm 3$ \\
\hline IV & 8 & 5.98 & 87.16 & 5.21 & $14 \pm 2$ \\
\hline $\mathrm{V}$ & 8 & 5.34 & 77.65 & 4.15 & $11 \pm 3$ \\
\hline
\end{tabular}

aThe presence of OBs in a cell was the criterion of its infection with BmNPV.

${ }^{b}$ Calculated by multiplying the cell number by percentage infection.

${ }^{\mathrm{c}} \mathrm{Mean} \pm$ standard error (SE)

show much cell lysis even after $96 \mathrm{hr}$ pi. The lysis of NIAS-MaBr-92 cells started at $172 \mathrm{hr}$ pi. In the present study, DZNU-Bm-1 showed an average of $21 \mathrm{OBs} /$ cell, whereas DZNU-Bm-12 gave an average yield of about $10 \mathrm{OBs} /$ cell over five passages. All three cell lines have a higher susceptibility to BmNPV than BmN cell line that has been reported to give $64 \%-73 \%$ of infection [27].

\section{CONCLUSION}

The results point that DZNU-Bm-1 and DZNU-Bm-12 cell lines are better than NIAS-MaBr-92 in terms of percentage infection in MGM-448 culture medium. The yield of OBs per infected cell is the highest in DZNU-Bm-1, whereas DZNU-Bm-12 and NIASMaBr-92 have comparable yields of OBs per cell. These cell lines should be adapted to low-cost serum-free media and checked for percentage infection and OB yield. Furthermore, the cell lines should also be screened for susceptibility to other baculoviruses such as HaNPV to ascertain their efficiency for the large-scale production of such biopesticides.

\section{ACKNOWLEDGMENTS}

The author would like to thank Dr. A.M. Khurad, former Head, P.G.T.D. Zoology, RTM, Nagpur University Campus, Nagpur, for providing cell lines and insightful guidance for this study. The author is also grateful to the Centre for Sericulture and Biological Pest Management Research (CSBR), Ambavihar, R.T.M. Nagpur University, Nagpur, for providing BmNPV inoculum.

\section{CONFLICT OF INTEREST}

The authors declare that they do not have any conflicts of interest.

\section{FINANCIAL SUPPORT}

None.

\section{REFERENCES}

1. Kost TA, Condreay JP, Jarvis DL. Baculovirus as versatile vectors for protein expression in insect and mammalian cells. Nat Biotechnol 2005;23:567-75.

2. Van Oers MM, Pijlman GP, Vlak. Thirty years of baculovirus-insect cell protein expression: from dark horse to mainstream technology. J Gen Virol 2015;96(Pt 1):6-23.

3. Drugmand JC, Schneider YJ, Agathos SN. Insect cells as factories for biomanufacturing. Biotechnol Adv 2012;30(5):1140-57.

4. Airenne KJ, Hu YC, Kost TA, Smith RH, Kotin RM, Ono C, et al Baculovirus. An insect-derived vector for diverse gene transfer applications. Mol Ther 2013;21(4):739-49.

5. Groner A. Specificity and safety of baculoviruses. In: Granados RR, Federici BA (eds.). The biology of baculoviruses, Vol. II. Boca Raton, FL: CRC Press, pp 178-96, 1987.

6. Entwistle PF, Evans HF. Viral control. In: Gilbert LI, Kerkut GA (eds.). Comprehensive insect physiology, biochemistry and pharmacology. Oxford Press, Oxford, UK, pp 347-412, 1985.

7. Carbonell LF, Hodge M R, Tomalski M D, Miller LK. Synthesis of gene coding for an insect-specific scorpion neurotoxin and attempts to express it using baculovirus vectors. Gene 1988;73:409-18.

8. Hoover K, Herrman R, Moskowitz H, Bonning, B, Duffey S. The potential of recombinant baculoviruses as enhanced bioinsecticides. Pestic Outlook 1991;7:21-7.

9. Hernandez-Crespo P, Hails RS, Sait, SM, Green BM, Timothy MC, Cory JS. Response of hosts of varying susceptibility to a recombinant baculovirus insecticide in the field. Biol Con 1999;16(2):119-27.

10. Kato T, Kajikawa M, Maenaka K, Park EY. Silkworm expression system as a platform for technology in life science. Appl Microbiol Biotechnol 2010;85:459-70. 
11. Agathos S. Insect cell culture. In: Baltz R, Demaine A, Davies J, Bull A, Junker B, Katz L, et al (eds.). Manual of industrial microbiology and biotechnology. 3rd edition, ASM Press, Washington DC, pp 212 $22,2010$.

12. Maeda S. Increased insecticidal effect by a recombinant baculovirus carrying a synthetic diuretic hormone gene. Biochem Biophys Res Commun 1989;165:1177-83.

13. Maeda S, Volrath SL, Hanzlink TN, Harper SA, Majima, K, Maddox DW, et al. Increased insecticidal effect of an insect specific neurotoxin expressed by a recombinant baculovirus. Virology 1991;184:777-80.

14. Pant U, Sudeep AB, Athawale SS, Vipat VC. Baculovirus studies in new, indigenous lepidopteran cell lines. Indian J Exp Biol 2002;40:638.

15. Qureshi SO. Comparative studies on susceptibility and occlusion body yield of Bombyx mori nucleopolyhedrovirus (BmNPV) in two heterologous cell lines. Trends Biosci 2017;10(10):1958-60.

16. Khurad AM, Kanginakudru S, Qureshi SO, Rathod MK, Rai, MM, Nagaraju J. A new Bombyx mori larval ovarian cell line highly susceptible to nucleopolyhedrovirus. J Invertebr Pathol 2006;92:5965.

17. Khurad AM, Zhang MJ, Deshmukh CG, Bahekar RS, Tiple AD, Zhang CX. A new continuous cell line from larval ovaries of silkworm, Bombyx mori. In vitro Cell Dev Biol Anim 2009;10:1007.

18. Mitsuhashi J, Shozawa A. Continuous cell lines from larval haemocytes of the cabbage armyworm, Mamestra brassicae. Develop Growth Differ 1985;27:599-606.

19. Bahekar RS, Qureshi SO. Study of some morphological and chromosomal parameters for the characterization of three indigenously developed ovarian cell lines of Bombyx mori (L). Biosci Biotechnol Res Commun 2013;6(1):28-31.

20. Raghow R, Grace TDC. Studies on a nuclear polyhedrosis virus in Bombyx mori cell in vitro. I. Multiplication kinetics and ultrastructural studies. J Ultrastruct Res 1974;47:384-99.
21. Granados RR, Lawler KA. In vivo pathway of Autographa californica baculovirus invasion and infection. Virology 1981;108:297-308.

22. Sohi SS, Percy J, Arif BM, Cunningham JC. Replication and serial passage of a singly enveloped baculovirus of Orgyia leucostigma in homologous cell lines. Intervirology 1984;21:50-60.

23. Lynn DE, Hink WF. Comparison of nuclear polyhedrosis virus replication in five lepidopteran cell lines. J Invertebr Pathol 1980;35:234-40.

24. Chakraborty S, Reid S. Serial passage of a Helicoverpa armigera nucleopolyhedrovirus in Helicoverpa zea cell cultures. J Invertebr Pathol 1999;73(3):303-8.

25. Lua HLL, Pedrini MRS, Reid S, Robertson A, Tribe D. Phenotypic and genotypic analysis of Helicoverpa armigera nucleopolyhedrovirus serially passaged in cell culture. J Gen Virol 2002;83:945-55.

26. Qureshi SO, Tiple AD, Khurad AM. Ultrastructural observations on the events of BmNPV infection in DZNU-Bm-1 (Bombyx mori) cell line. Biosci Biotechnol Res Commun 2009;2(2):149-54.

27. Funakoshi M, Aizawa K. Effect of inhibitors on the replication of a nuclear polyhedrosis virus of the silkworm, Bombyx mori. In: Kuroda Y, Kurstak E, Maramorosch K (eds.). Invertebrate and fish tissue culture, Springer-Verlag, New York, pp 155-8, 1988.

\section{How to cite this article:}

Qureshi SO. Studies on cytopathic effects of BmNPV infection in three lepidopteran insect cell lines in MGM-448 medium. J Appl Biol Biotech 2020;8(03):013-016. DOI: 10.7324/JABB.2020.80303 